\title{
Deaths in the 3 May 1999 Oklahoma City Tornado from a Historical Perspective
}

\author{
Harold E. Brooks and Charles A. Doswell III* \\ NOAA/National Severe Storms Laboratory, Norman, Oklahoma \\ (Manuscript received 5 February 2001, in final form 6 July 2001)
}

\begin{abstract}
The 3 May 1999 Oklahoma City tornado was the deadliest in the United States in over 20 years, with 36 direct fatalities. To understand how this event fits into the historical context, the record of tornado deaths in the United States has been examined. Almost 20000 deaths have been reported associated with more than 3600 tornadoes in the United States since 1680. A cursory examination of the record shows a break in 1875 . Prior to then, it is likely that many killer tornadoes failed to be reported. When the death toll is normalized by population, a near-constant rate of death is apparent until about 1925, when a sharp fall begins. The rate was about 1.8 people per million population in 1925 and was less than 0.12 people per million by 2000 . The decrease in fatalities has resulted from two primary causes: a decrease in the number of killer tornadoes and a decrease in the number of fatalities in the most deadly tornadoes. Current death rates for mobile home residents, however, are still nearly what the overall national rate was prior to 1925 and are about 20 times the rate of site-built home residents. The increase in the fraction of the U.S. population living in mobile homes has important implications for future reductions in the death toll.
\end{abstract}

\section{Introduction}

Tornadoes are a hazard to life and property everywhere, including in the United States. A recent analysis of historical changes in damage associated with major tornadoes has shown that, if the damage amounts are adjusted for wealth of the country, there is no clear longterm trend in the damage caused by the most damaging tornadoes (Brooks and Doswell 2001). In this followup work, we examine the question of changes in the record of tornado deaths in the United States, focusing primarily on the annual number of deaths, killer tornadoes, and fatalities per tornado. As is the case with the damage dataset, there are issues involved in the use of the data that must be addressed. After discussing those issues, we will look at the long-term record in an effort to determine changes through time. We will close by considering possible future trends in tornado fatalities.

These considerations provide a background for understanding the fatalities in the 3 May 1999 tornado outbreak. The particular tornado that hit the metropolitan Oklahoma City area directly killed 36 people, the most in the United States since the 10 April 1979 Wich-

\footnotetext{
* Current affiliation: Cooperative Institute for Mesoscale Meteorological Studies, The University of Oklahoma, Norman, Oklahoma.

Corresponding author address: Harold E. Brooks, NOAA/NSSL, 1313 Halley Circle, Norman, OK 73069.

E-mail: brooks@nssl.noaa.gov
}

ita Falls, Texas, tornado killed 42 (see Table 1 for a record of the most fatalities in a single U.S. tornado going backward in time from the end of 2000). The total number of direct fatalities in the outbreak was 46, the most in the United States since the Ohio-Pennsylvania outbreak of 31 May 1985 killed 76. Of the 36 fatalities in the Oklahoma City tornado, 11 occurred in mobile homes, and 18 of the 46 deaths caused by tornadoes in the outbreak were mobile home residents. As we will discuss later, the problem of mobile home safety is the biggest obstacle to reduction of tornado deaths in the United States.

\section{The dataset and concerns}

The primary dataset to be used is that of Grazulis (1993, hereinafter G93, 1995), listing tornadoes with fatalities up through 1995. From 1996 to 2000, the records are those collected by the National Oceanic and Atmospheric Administration Storm Prediction Center (SPC 2001). According to G93, the first death from a tornado in the United States was recorded in 1680 in Cambridge, Massachusetts. Tornado fatalities were reported infrequently over the following two centuries, and tornadoes with at least 10 fatalities were reported very rarely. From 1680 to 1874 , only four tornadoes that caused at least 10 deaths were recorded. In contrast, seven were recorded in the decade that followed. As a result, the primary emphasis of this paper is on the period of 1875-2000. Along with the apparent break in the number of tornadoes with at least 10 fatalities, an- 
TABLE 1. Most fatalities in a single tornado in the United States going back in time from the end of 2000. Location is most prominent site or sites hit by tornado.

\begin{tabular}{llc}
\hline \hline \multicolumn{1}{c}{ Date } & \multicolumn{1}{c}{ Location } & Deaths \\
\hline 16 Dec 2000 & Englewood, AL & 11 \\
3 May 1999 & Oklahoma City, OK & 36 \\
10 Apr 1979 & Wichita Falls, TX & 42 \\
21 Feb 1971 & Cary-Pugh City, MS & 58 \\
25 May 1955 & Blackwell, OK-Udall, KS & 80 \\
9 Jun 1953 & Worcester, MA & 94 \\
8 Jun 1953 & Flint, MI & 115 \\
9 Apr 1947 & Woodward, OK & 181 \\
6 Apr 1936 & Gainesville, GA & 203 \\
5 Apr 1936 & Tupelo, MS & 216 \\
18 Mar 1925 & Tristate (MO-IL-IN) & 695 \\
\hline
\end{tabular}

other reason for concentrating on the period beginning in 1875 is clear when the number of killer tornadoes ${ }^{1}$ per year is considered (Fig. 1). In 1875, a large increase in the number of reports in the record occurred, with 30 killer tornadoes in that year alone. The sudden increase in reports is likely due to the work of John Park Finley (Galway 1985), who began his work in collecting tornado reports in the late 1870 s.

It seems plausible, given the abrupt change in the number of killer tornadoes, that many killer tornadoes prior to 1875 went unreported. Given the rapid change in demographics in the United States in the nineteenth century, it is extremely difficult to estimate the amount of underreporting. Even since then, it is likely that some killer tornadoes have gone unreported, although underreporting is probably less of a problem since 1875 .

The number of deaths caused by individual tornadoes is not always known well, particularly for earlier tornadoes. G93 reports that possible deaths of slaves in the 1840 Natchez, Mississippi, tornado are not recorded, nor are deaths on boats in the Mississippi River in the 1896 Saint Louis-East Saint Louis tornado. The latter event also provides evidence of conflicting numbers of deaths from different sources. G93 lists the number of deaths in Saint Louis as 137 and East Saint Louis as 118, consistent with Curzon (1896), who published a book on the tornado within 2 weeks of the event. The East Saint Louis Journal newspaper (Cook and Reed 2001) listed 128 deaths in East Saint Louis 4 days after the tornado, and Williams (1999) lists 140 dead in Saint Louis, giving a total of 268 . We will use the G93 numbers throughout, with the caution that the exact number of deaths in many events cannot be known.

Another problem involves determining precisely which deaths are tornado related. In the case of the 3 May 1999 Oklahoma City tornado, 36 people were killed directly by the tornado (e.g., hit by debris or thrown long distances), but several others could be viewed as indirect deaths. For instance, at least two people died of heart attacks in the vicinity of the damage

${ }^{1}$ A killer tornado is any tornado that causes one or more fatalities.

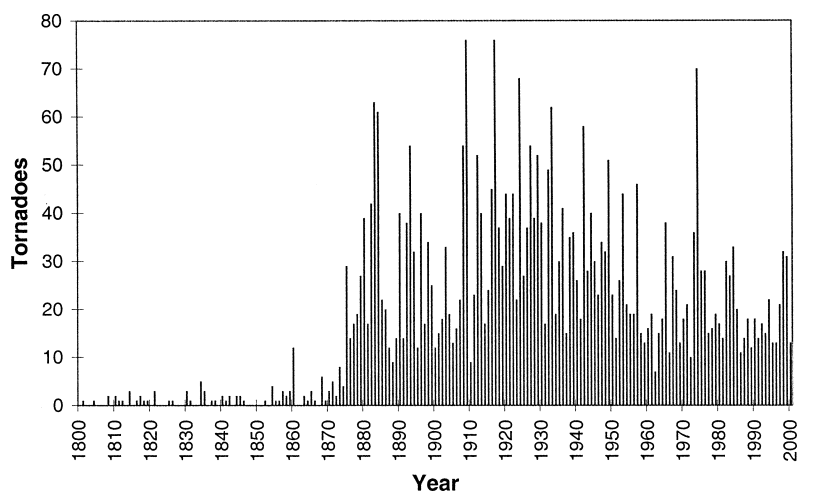

FIG. 1. Killer tornadoes per year in the United States, 1800-2000.

path, a third died in a fall trying to get into a storm shelter outside of the tornado's exact path, and another died when candles, lit after his electrical power had gone off because of the tornado, caught his residence on fire (Brown et al. 2002). The traditional National Weather Service procedure has been to consider only the direct fatalities, but determining that information, particularly early in the record, is impossible. There is no way to know how many of the deaths within the record are indirect, so there is a possible problem of inhomogeneity in the dataset.

\section{General features of the record}

The number of deaths per year caused by tornadoes has generally been much less in the last quarter of the twentieth century than it was previously (Fig. 2). In particular, the number of deaths in the "big years" has dropped dramatically. From 1975 to 2000, only twice did as many as 100 tornado deaths occur in a year (1984 and 1998). In contrast, that number occurred 54 times from 1875 to 1974 , including every year from 1916 through 1927. The 1910s through the middle 1930s, in fact, represent a period of very high fatalities, as shown by the smoothed curve in Fig. 2. From 1912 to 1936, the mean annual death toll was 260, almost 5 times as many as in 1976-2000, when the mean was 54 . The medians for the two periods were 179 and 44, respectively, indicating that the means are somewhat unrepresentative, having been influenced by a few extreme events on the high end.

The decrease in death toll is even more apparent when the rate of death is normalized by the population of the United States, available from the U.S. Census Bureau ${ }^{2}$ (Fig. 3). Prior to 1925, the smoothed rate was relatively

\footnotetext{
${ }^{2}$ All population figures in this paper were taken from U.S. Census Bureau Web site (http://www.census.gov/). The population figures used for Fig. 3 were the 1 July annual estimates from 1900 to 1999 (http://www.census.gov/population/estimates/nation/popclockest.txt). Prior to 1900 , population was assumed to increase linearly between the decennial censuses. For 2000, the change from 1998 to 1999 was added to the 1999 figures.
} 


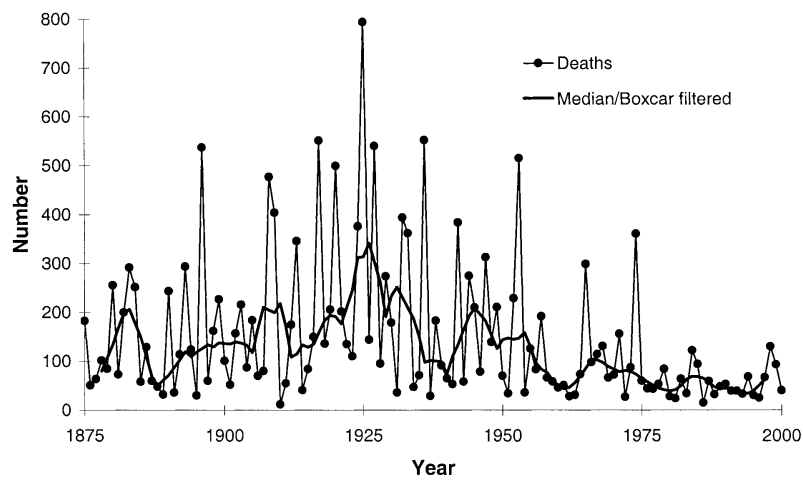

FIG. 2. Deaths per year in tornadoes in the United States, 18752000. The light line with dots shows raw values. The heavy line shows the smoothed values. The smoother consists of finding the median of three consecutive values and then applying a running mean over five medians.

constant, showing a slight increase from about 1.6 to 1.8 per million. Since that time, however, the rate has decreased substantially, to a little over 0.11 per million, roughly $1 / 15$ th of the long-term average prior to 1925 . Many factors, including the beginnings of tornado forecasting, improved communications, spotter networks, and changes in construction, likely have been involved in this decrease [see Doswell et al. (1999) for more discussion]. There is no simple way to deconvolve the possible contributions from all those factors, so we do not assign a relative importance to any of them in particular. To put the change into perspective, however, a death rate of 1.8 per million people per year would have resulted in approximately 500 deaths in 2000, as compared with the actual number of 40. Another way of looking at this change is to consider the impact on the death toll associated with the Oklahoma City tornado. A crude estimate of the death rate prior to the changes that occurred in 1925 can be obtained via multiplying the death toll by the change in the rate. Such an estimate applied to Oklahoma City gives a death toll of 540, implying that the efforts (intentional or unintentional) to improve tornado safety saved over 500 lives on 3 May 1999. Large caveats obviously must be associated with such an estimate, but it is of the same order as the estimate of 700 deaths based on the changes in the historical ratio of deaths to amount of damage in tornadoes (Doswell et al. 1999; Brooks and Doswell 2001).

A long-term decrease in the tornado death rate also means that the notion of an "average" tornado death toll is somewhat difficult to define. Taking a standard climatological period of 30 years makes little sense, given the presence of such a strong trend. A more reasonable approach might be to look at the expected value of the trend at whatever point on the time series is of interest. In 2000, with the value of 0.12 per million and a population of almost 280 million, the expected death toll would be about 34 , one-half of the 30 -yr mean value of 68. The decrease in the death toll also has changed

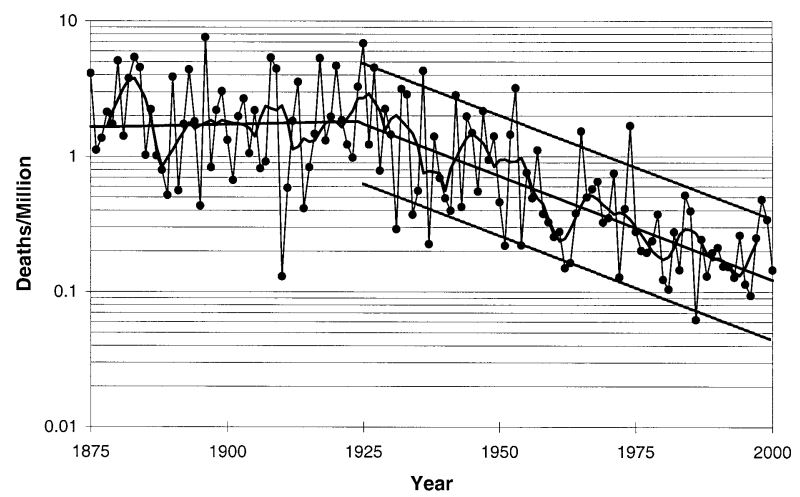

FIG. 3. Death rate per million people per year in the United States, 1875-2000. The thin line with dots is the raw rate, the curved thick line is the death rate, filtered by three-point median and five-point running mean filter, and the straight solid lines are least squares fits to the filtered death rate for 1875-1925 and 1925-2000. Dashed lines are estimates of 10th and 90th percentile death rates from 1925 to 2000 .

the perception of what is a big year for tornado deaths. Lines estimating the 90th percentile death rate from 1925 to 2000 have been constructed to be parallel to the mean value (Fig. 3). Multiplying the values of the 90th percentile by the population in 1925 and 2000 gives estimated values of 475 and 80 deaths per year at those two times. From this perspective, the 1998 national death toll of 130 was just as far above the expected number of deaths as the 1925 national death toll of 794 (most of which came from the single "Tri-state" tornado). In fact, the 10th percentile value in 1925 is 61, so that a rare low death toll 75 years ago is almost as big as a rare high death toll now.

We cannot identify the underlying social and scientific reasons behind the decline in tornado deaths, but we can at least attempt to describe from a statistical perspective how the decrease has occurred. First, the number of killer tornadoes is, in general, less than it was $75 \mathrm{yr}$ ago (see Fig. 1). The median number of killer tornadoes per year from 1976 to 2000 was 17 and the maximum was 33. In contrast, the median from 1912 to 1936 was 39 and the minimum was 17 .

Arguably more important than the number of killer tornadoes, the number of deaths from individual "highdeath" tornadoes has decreased. This fact can be seen in at least two different ways. First, we can define a high-death tornado and examine how that definition changes with time. For direct comparison to the 3 May 1999 tornado, we could first consider the frequency of tornadoes associated with at least 36 deaths. Recall that the Oklahoma City tornado was the first tornado in over 20 years to have such a large death toll. In the 1920 s and 1930s, 20 such tornadoes occurred. What was once an annual occurrence had not occurred for 20 years prior to 3 May 1999.

The use of the Oklahoma City death toll to set an arbitrary threshold for high death tolls is not completely 


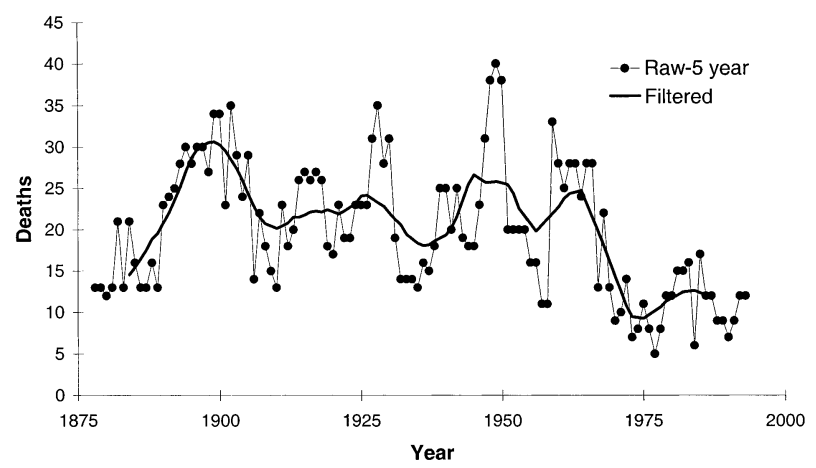

FIG. 4. Deaths in 95 th percentile tornadoes. The thin line with dots shows the raw value for 5-yr period, centered on plotted year. The heavy line shows the result of using a three-point median and 11-yr running mean.

satisfactory. Changes in the threshold could give different impressions and the results would be sensitive to the threshold. A simple, objective definition of a highdeath tornado is to take all killer tornadoes within a 5yr window and find the 95th percentile of the death tolls associated with those tornadoes (Fig. 4). Smoothing the 95th percentile value with a 3-point median filter, followed by an 11-point running mean, shows that it has dropped from 20-25 during the period of 1900-70 down to about $10-15$ since 1975 .

A second illustration of this is the return period of any particular value of the number of deaths in a single tornado. By return period, we mean the time between two events of the same magnitude. As an example, we have calculated how many days there were between two days with at least one 10-death tornado on them since 1875 as a function of time (Fig. 5). There are a total of 259 days with at least one 10-death tornado in that time period. Prior to 1958, return periods of less than 10 days were common. Since then, the fewest days between 10death tornado days has been 19 (between the Hall County, Georgia, 12-fatality tornado on 20 March 1998 and the Birmingham, Alabama, 32-fatality tornado on 8 April 1998).

We can compare the return period for 10-death tornadoes to the population of the United States. By smoothing the return periods with a strong 5-point median and 19-point running mean, a shortening of the return period is apparent prior to 1925 with a lengthening of the period since then (Fig. 6). In the absence of mitigation efforts, it might be expected that the return period would have an inverse relationship to population. During the period before 1925, this is roughly true. Since then, however, as population has continued to increase, the return period has increased. Again, we cannot identify exactly why, but it seems likely that improved forecasting, communications, spotter networks, and construction have provided significant mitigation of the life-threatening consequences of tornadoes.

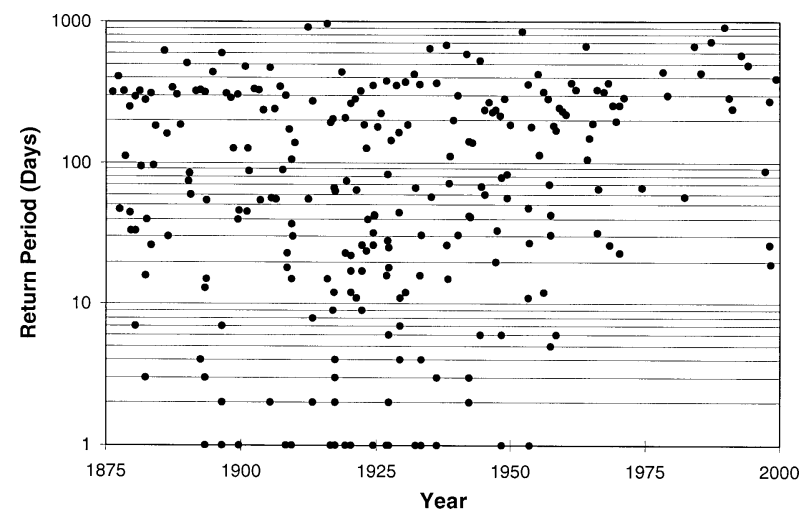

FIG. 5. Days between days with at least one 10-fatality tornado (return period). Points are plotted at the second date of each pair.

\section{The mobile home problem}

An increase of the death rate for mobile home residents in tornadoes was dramatically apparent in the Oklahoma City tornado. Eleven of the deaths occurred in mobile homes, but less than 100 mobile homes were damaged by the tornado, in comparison with several thousand permanent homes. Specific figures for the number of people in each kind of housing are not available for the damaged structures, but a conservative estimate is that the death rate in mobile homes was more than one person per 10 units while the death rate in permanent homes was less than one person per 200 units. Thus, the risk to mobile home residents was at least 20 times as great as the risk to permanent home residents in the Oklahoma City tornado.

We can compare the Oklahoma City tornado with other tornadoes to see whether this increased risk holds true and to see what kind of changes have been occurring. Since 1975, the National Weather Service has separated out tornado fatalities associated with mobile homes. Data for other fatality locations (permanent ${ }^{3}$ homes, other buildings, vehicles, outdoors) are available online from the Storm Prediction Center (http:// www.spc.noaa.gov/climo/), starting with 1985 (Table $2)$. The fraction of deaths occurring in mobile homes has been increasing since 1975 (Fig. 7). Using a Kendall's tau test (Press et al. 1992), the increase is statistically significant at the $95 \%$ confidence level. From 1976 to $1980,24 \%$ of tornado deaths were in mobile homes. That fraction increased to $34 \%$ in $1986-90$ and to $50 \%$ from 1996 to 2000 .

To understand the increase, we need to look at the changing demographics of the United States. The Census Bureau carries out a housing survey with the decennial census to determine the number of different

\footnotetext{
${ }^{3}$ Definitions are not universally accepted. "Permanent" homes are often referred to as "site built" and "mobile homes" are often referred to as "manufactured housing."
} 


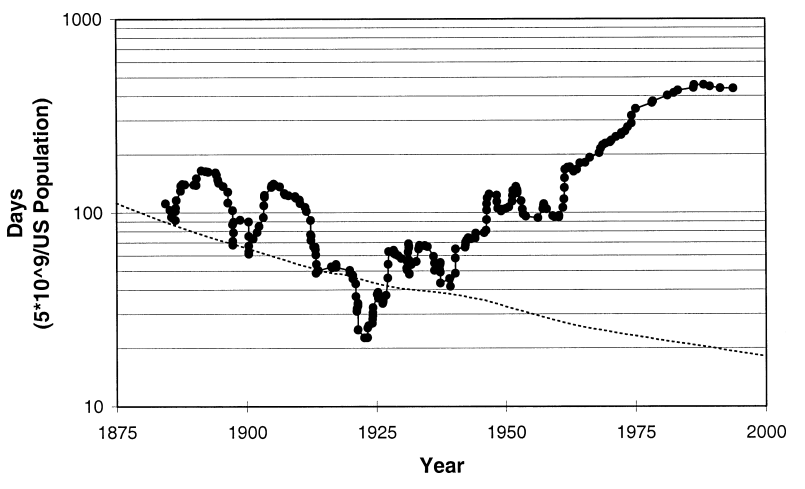

FIG. 6. Smoothed 10-fatality tornado return period (5-point median, 19-point running mean) in days (dots with solid line) as compared with 5 billion divided by U.S. population (dashed line).

kinds of housing units in use in the United States. ${ }^{4}$ The mobile home fraction of housing units in the United States has increased significantly since 1950 (Table 3). If one assumes the number of people in different kinds of housing is the same for each kind of unit, that means that 10 times as many people lived in mobile homes in 1990 as in 1950 . We can use these data to calculate the rate of fatalities in each kind of housing per million people, in a way similar to Fig. 3. For simplicity, we have assumed that the fraction of housing units changed linearly between the years the housing surveys were done and that the increase from 1980 to 1990 continued after 1990. The rate of death in mobile homes is dramatically higher than in permanent homes (Fig. 8). The mean (median) annual death rate from 1975 to 2000 in mobile homes was 1.23 (1.19) per million per year, whereas the mean (median) rate from 1985 to 2000 in permanent housing was $0.06(0.04)$ per million per year. In short, the death rate is approximately 20 times as high in mobile homes as in in permanent homes, and the mobile home rate is about $70 \%$ of the rate for the total U.S. population prior to 1925 . The 20 -times-greater death rate for mobile home residents since 1985 is consistent with the estimate we derived earlier for the Oklahoma City tornado.

There are no statistically significant trends in the rate of deaths over the time period of record for mobile home or permanent home residents, based on Kendall's tau test. The increase in the fraction of deaths occurring in mobile homes is a result of the increasing fraction of the population of the United States living in mobile homes.

The effect of the increasing population in mobile homes is important for the number of deaths in tornadoes nationally and may be especially serious in the future. We can make a simple model of the effect of mobile homes by using the population in mobile homes that underlies Fig. 8 and by assuming that the average

\footnotetext{
${ }^{4}$ The results of the 2000 housing survey were not available as of March 2002.
}

TABLE 2. Annual tornado deaths by type of housing in the United States, 1975-2000. Total is the total number of deaths, mobile is the number of mobile home deaths, and permanent is number of permanent ("site built") housing deaths.

\begin{tabular}{cccc}
\hline \hline Year & Total & Mobile & Permanent \\
\hline 1975 & 60 & 13 & - \\
1976 & 44 & 18 & - \\
1977 & 43 & 7 & - \\
1978 & 53 & 15 & - \\
1979 & 84 & 9 & - \\
1980 & 28 & 11 & - \\
1981 & 24 & 14 & - \\
1982 & 64 & 20 & - \\
1983 & 34 & 20 & - \\
1984 & 122 & 43 & - \\
1985 & 94 & 28 & 40 \\
1986 & 15 & 7 & 3 \\
1987 & 59 & 24 & 7 \\
1988 & 32 & 21 & 6 \\
1989 & 48 & 12 & 8 \\
1990 & 53 & 7 & 11 \\
1991 & 39 & 20 & 3 \\
1992 & 39 & 20 & 18 \\
1993 & 33 & 13 & 6 \\
1994 & 68 & 26 & 14 \\
1995 & 30 & 8 & 15 \\
1996 & 25 & 14 & 8 \\
1997 & 67 & 30 & 23 \\
1998 & 130 & 65 & 40 \\
1999 & 93 & 39 & 35 \\
2000 & 40 & 31 & 4 \\
\hline & & &
\end{tabular}

death rate in mobile homes occurred each year since 1960. Further assuming that the mobile home population will continue to increase as it has, we can estimate the number of deaths in mobile homes in the future. Taking that number and dividing it by the total U.S. population gives a death rate for the total U.S. population if all deaths outside of mobile homes were eliminated. We can compare the model death rate to the long-term trend seen in Fig. 3 (Fig. 9). The mobile home rate is approaching the long-term overall trend and, in fact, will soon pass it. The raw data after 1990 in Fig. 3 could be interpreted as showing that the long-term decline has stopped and that the death rate has leveled off, although it is too early to be sure of this change. Thus, the increase in mobile home residency may have reversed the approximately 70 -year-long trend of decreasing death rates in tornadoes. Only time will tell what the trend will be or if efforts to target this vulnerable population will help to reduce deaths.

The increase in mobile homes as housing has been particularly large in the southeastern United States (Fig. 10). Given that this part of the United States gets a large number of tornadoes and that many of them happen overnight when getting messages to people is particularly difficult, as shown by the tornadoes in Orlando, Florida (1998), Hall County, Georgia (1998), and Camilla, Georgia (2000), this is an area of great concern. Improvements in the accuracy and lead time of forecasts and warnings may have little effect on decreasing deaths 


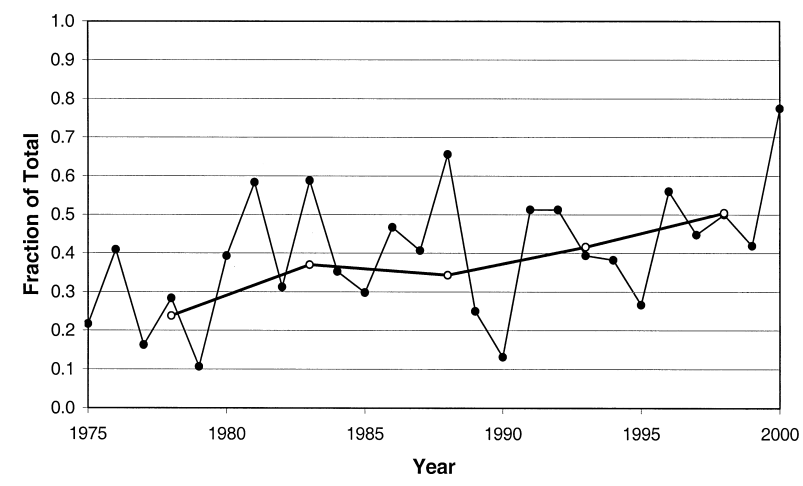

FIG. 7. Fraction of total deaths occurring in mobile homes, 19752000. Thin line with solid dots is for individual years and thick line with open dots is for 5-yr average, with points plotted at the center of each period.

if the problem of mobile home deaths cannot be addressed. The issues associated with mobile home deaths are clearly nonmeteorological, involving construction practices, availability of adequate shelters, availability of alternate housing, and the ability to communicate warning information to residents. Realistic solutions lie far beyond the scope of meteorology.

\section{The Oklahoma City tornado: The possible role of education}

One of the more intriguing aspects of the demographics of fatalities associated with the Oklahoma City tornado is the absence of any deaths from the age of 5 through 23 years old. If we compare this to the average distribution of deaths from other tornadoes in the 1990s, the gap is striking (Fig. 11). If we assume that the 1990s distribution represents the typical distribution of deaths by age associated with tornadoes, we can estimate how likely it is that the gap associated with the Oklahoma City tornado would occur by chance. To do so, we randomly select 36 ages from the distribution associated with the 1990s, and repeat for a large number of trials. The result is that the probability of such a gap is less than 1 in 3000 .

There are many possible reasons for the gap. One is that there were few residents of damaged structures in that age range. We do not have complete demographic information on the residents of the damaged houses (note that data on the level of census tracts would be

TABLE 3. Percentage of housing units in the United States broken down by mobile and permanent housing from U.S. Census Bureau decennial housing survey.

\begin{tabular}{ccc}
\hline \hline & Mobile & Permanent \\
\hline 1950 & 0.7 & 99.3 \\
1960 & 1.3 & 98.7 \\
1970 & 3.1 & 96.9 \\
1980 & 5.1 & 94.9 \\
1990 & 7.2 & 92.8 \\
\hline
\end{tabular}

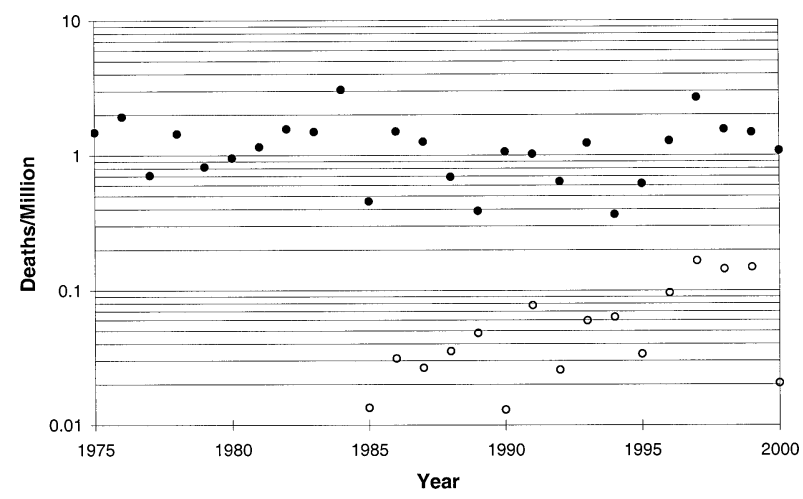

FIG. 8. Death rate per million people per year in the United States for mobile home residents (1975-2000, solid dots) and permanent home residents (1985-2000, open dots).

unable to resolve the affected housing), but information is available from one subset of the damage track. Officials of the Moore Public Schools, whose district includes much of the damage track in south Oklahoma City and Moore, estimated that there were approximately 1800 students from their schools that lived in houses that were either seriously damaged or destroyed by the tornado (S. Couch 1999, personal communication). Thus, it seems unlikely that the tornado preferentially traveled through a region of few students. Only 6 of the 1800 Moore students were hospitalized, and none were killed.

Another possible reason for this gap is education of the students. An informal survey of 130 junior high school students in two of the Moore schools with the largest numbers of damaged structures, conducted 2 weeks after the tornado, indicated that approximately $85 \%$ of the students took some precautionary actions (e.g., going into an interior bathroom or closet). Of those, all but one sought shelter in locations recommended by National Weather Service guidance. Seventy percent of the students surveyed indicated that they had

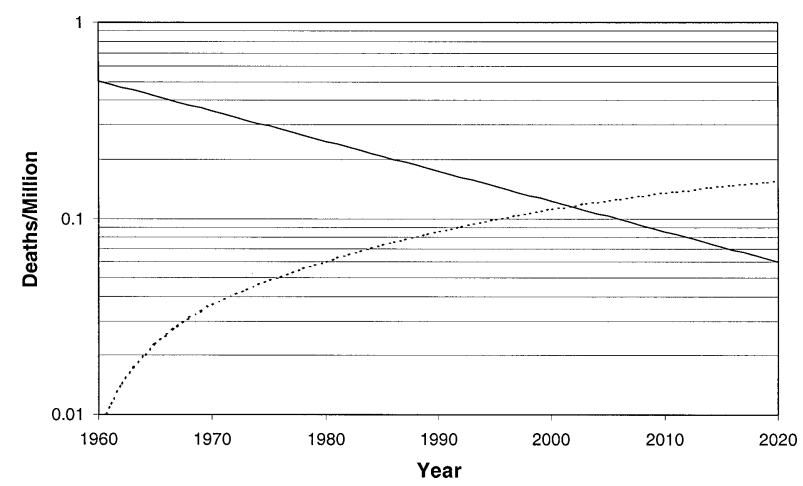

FIG. 9. Long-term trend in tornado death rate in the United States, based on 1925-2000, extrapolated out to 2020 (solid line), and death rate from model based on mean annual death rate in mobile homes, assuming no deaths occur except in mobile homes and that historical increase in fraction of U.S. population living in mobile homes will continue (dashed line). 


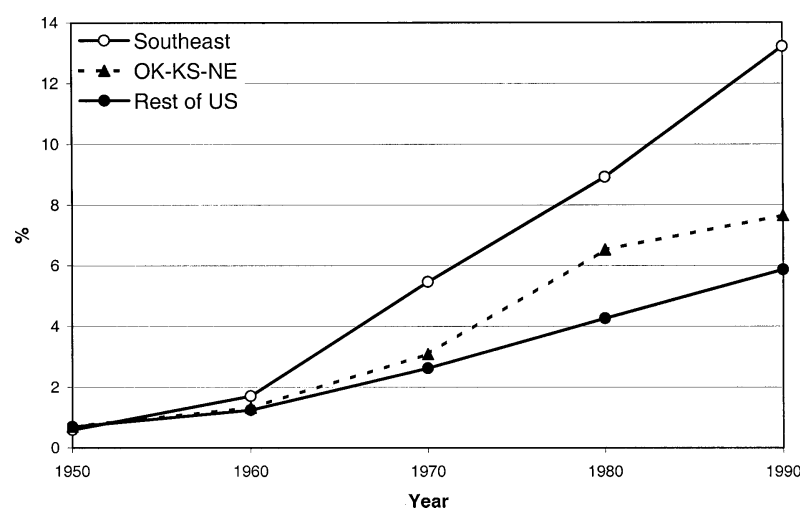

FIG. 10. Fraction of total housing units that are mobile homes, based on U.S. Census Bureau decennial survey of housing. Southeastern states, including AR, LA, MS, AL, GA, FL, TN, NC, and SC (solid line with open dots); central plains states, including OK, KS, and NE (dashed line with triangles); and rest of the United States (solid line with solid dots) are shown.

learned tornado safety precautions as part of their education at school (S. Couch and K. Parrish 1999, personal communication). At one of the schools, tornado safety had been covered as part of the eighth-grade earth science classes on the Friday before the tornado hit on Monday. Although we cannot prove a causal relationship, it is plausible to suggest that education of school children was a strong contributor to the absence of fatalities among that age group.

\section{Summary}

More than 18000 people died in tornadoes in the United States from 1875 to 2000 . The rate of death has been decreasing since 1925 from about 1.8 per million per year to 0.12 per million per year. This has resulted both from fewer killer tornadoes and from a decrease in the number of deaths in the largest-fatality tornadoes. What used to be considered a relatively common number of fatalities, both from the perspective of a single tornado and annual death tolls, is now an extremely large number. The 3 May 1999 Oklahoma City tornado was the largest death toll in over 20 years. However, the direct toll of 36 lives would have been a common number in the 1920s and 1930s. Simple estimates of the total death toll that would have occurred in Oklahoma City, without the meteorological and sociological changes that led to the long-term decrease in death tolls, give values on the order of 500 or more. We cannot determine the importance of the various factors that have helped the decrease, so we cannot isolate the importance of forecasting or any other particular activity contributing to the overall reduction.

There remains one particularly vulnerable group of people in the United States, residents of mobile homes. The rate of death for mobile home residents is relatively close to the pre-1925 values in the United States. The increase in use of mobile homes for housing has meant

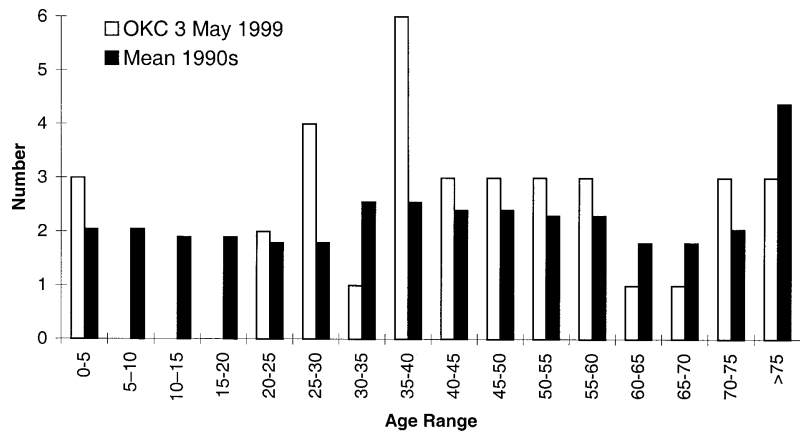

FIG. 11. Deaths associated with the Oklahoma City tornado (open bars) and average number in age group per 36 fatalities in other tornadoes in 1990s (black bars). Label 0-5 indicates from birth to 5th birthday, 5-10 from 5th birthday to 10th birthday, etc.

that they are an increasingly large component of the overall death toll. One-half of all fatalities from 1996 to 2000 occurred in mobile homes, more than 2 times the fraction 20 years earlier. It seems likely that the fraction of deaths in mobile homes will continue to increase. Efforts to improve safety practices and communication of forecast and warning information for this group will be especially important in the future, if the long-term decrease in tornado fatalities in the United States is going to continue.

Based on the absence of fatalities among school-aged children in the Oklahoma City tornado and the results from a survey of junior high school students in the affected area, it seems likely that the education of children is an important aspect in promoting tornado safety. If we are going to expect people to take appropriate actions when tornado warnings are issued, it is imperative that they know what those actions should be. Conveying information about safety actions during "callto-action" statements as part of a tornado warning may not provide much help, if people have not considered what they are going to do prior to the issuance of the warning. Encouraging and assisting schools in the safety education seems to be a relatively low-cost and, potentially, high-return approach to lowering tornado deaths.

Acknowledgments. We thank Tom Grazulis for providing an electronic form of his database. Also, discussions and information from Debra Combs of the U.S. Centers for Disease Control and Prevention and Pam Archer of the Oklahoma State Department of Health were helpful, particularly in illuminating the problem of indirect fatalities. Steve Couch of Moore Central Junior High School and Kate Parrish of Highland West Junior High School carried out the survey of students and provided information about the demographics of damaged housing in the Moore Public School District. The anonymous reviewers provided helpful suggestions for improving the presentation. 


\section{REFERENCES}

Brooks, H. E., and C. A. Doswell III, 2001: Normalized damage from major tornadoes in the United States: 1896-1999. Wea. Forecasting, 16, 168-176.

Brown, S., P. Archer, E. Kruger, and S. Mallonee, 2001: Tornadorelated deaths and injuries in Oklahoma due to the 3 May 1999 tornadoes. Wea. Forecasting, 17, 343-353.

Cook, S., and S. Reed, cited 2001: List of tornado dead and injured. [Available online at http://www.iltrails.org/stclair/tor3.htm.]

Curzon, J., Ed.,1896: The Great Cyclone at St. Louis and East St. Louis, May 27, 1896. Cyclone Publishing Company, 422 pp. [Republished 1997 by Southern Illinois University Press, 422 pp.]

Doswell, C. A., III, A. R. Moller, and H. E. Brooks, 1999: Storm spotting and public awareness since the first tornado forecasts of 1948. Wea. Forecasting, 14, 544-557.

Galway, J. G., 1985: J. P. Finley: The first severe storms forecaster. Bull. Amer. Meteor. Soc., 66, 1389-1395.

Grazulis, T. P., 1993: Significant Tornadoes, 1680-1991. Environmental Films, 1326 pp.

, 1995: Significant Tornadoes. Update, 1992-1995. Environmental Films, 118 pp.

Press, W. H., W. A. Teukolsky, W. T. Vetterling, and B. P. Flannery, 1992: Numerical Recipes in FORTRAN. The Art of Scientific Computing. 2d ed. Cambridge University Press, 963 pp.

SPC, cited 2001: Climatological data. [Available online at http:// www.spc.noaa.gov/climo/.]

Williams, S. K., cited 1999: Listing of known dead of St. Louis from the cyclone. [Available online at http://www.rootsweb.com/ $\sim$ mocstlou/cyclone.htm.] 